\title{
Pengaruh Social Media Marketing, Ekuitas Merek, dan Citra Destinasi Terhadap Minat Berkunjung ke Tempat Wisata
}

\author{
Isman, Ryan Gerry Patalo ${ }^{1}$, Dimas Eka Pratama ${ }^{2}$
}

1,2 Fakultas Ekonomi dan Bisnis Universitas Merdeka Malang

\section{Info Artikel}

Sejarah Artikel:

Diterima : 4 Juni 2020

Diperbaiki : 22 Juli 2020

Disetujui : 23 Juli 2020

Keywords:

social media marketing, brand equity, destination image, and visit intention

\section{Kata Kunci:}

social media marketing, ekuitas merek, citra destinasi, dan minat berkunjung

DOI:

https:/ / doi.org/10.21107/jsmb.v7i1.7447

Korespondensi:

Nama: Ryan Gerry Patalo

Email:vin.ryan06@gmail.com

\begin{abstract}
The purpose of this study was to determine the effect of social media marketing, Brand Equity and destination image on visiting intentions. The population in this study were all followers of Jatim Park 3 social media accounts in the form of facebook, by taking a sample of 150 people. Multiple linear regression and hypothesis testing are the analytical methods used, and the results of the research show that social media marketing influences visiting intentions. Brand Equity / Brand Equity affects the visiting intention. Destination image has no significant effect on visiting intention.
\end{abstract}

\begin{abstract}
Abstraks
Tujuan penelitian ini untuk mengatahui pengaruh Social media Marketing, Brand Equity/Ekuitas Merek dan Citra destinasi terhadap Minat berkunjung. Populasi dalam penelitian ini merupakan semua pengikut akun social media Jatim Park 3 berupa facebook, dengan mengambil sampel sebanyak 150 orang. Regresi linier berganda dan Uji hipotesis merupakan metode analisis yang digunakan, dan hasil penelitian menunjukan Social media marketing berpengaruh terhadap minat berkunjung. Brand Equity/Ekuitas Merek berpengaruh terhadap minat berkunjung. Citra destinasi tidak berpengaruh signifikan terhadap minat berkunjung.
\end{abstract}

ISSN: 2355-9643 (Print)

ISSN: 2460-3775 (on-line)

\section{PENDAHULUAN}

Internet merupakan salah satu tanda jika teknologi informasi saat ini telah berkembang pesat. Banyak hal positif yang bisa didapatkan dengan mudah pada kondisi saat ini. Di Indonesia jumlah pengguna internet dari tahun ke tahun meningkat secara pesat. Pengguna internet di Indonesia berjumlah 132,7 juta pengguna dan 130 juta diantaranya merupakan pengguna aktif di social media. Pengguna internet di Indonesia rata-rata tiap hari menggunakan internet selama 8-9 jam, dan mayoritas masyarakat Indonesia meng- akses internet menggunakan mobile phone (Jayani, 2019)

Kota Batu hampir setiap tahunnya terdapat penambahan wisata baru, salah satunya adalah Jatim Park 3 yang baru dibuka November 2017. Jatim Park 3 merupakan perpaduan konsep pariwisata dan pendidikan. Terdapat beberapa wahana yang ada di Jatim Park 3 yaitu; Dino Park, Galeri Musik Indonesia, Fun Tech Plaza, 6D Cinema, dsb. Tren social media marketing juga ditemukan dalam industri pariwisata di Indonesia. Jawa Timur Park 3 merupakan tempat hiburan dan edukasi baru yang berada di Kota Wisata 
Batu. Jatim Park 3 memang belum banyak diketahui oleh masyarakat luas, mengingat tempat wisata ini baru diresmikan di Bulan November 2017. Sehingga Jawa Timur Park 3 perlu gencar untuk melakukan kegiatan pemasaran guna mengenalkan produknya kepada masyarakat luas. Salah satunya melakukan kegiatan pemasaran melalui social media. Namun, Jawa Timur Park 3 belum dapat memaksimalkan pemasaran melalui social media dengan baik. Terlihat pada akun social media yang dimiliki, Jatim Park 3 tidak sering melakukan posting, membangun interaksi dengan pengikut, dan belum bisa menghasilkan konten yang trend. Sehingga dibutuhkan adanya inovasi dalam pemasaran yang dilakukan pada social media dan memperhatikan semua aspek dalam minat wisatawan yang akan berkunjung (Alvianna et al., 2020).

Dalam persaingan bisnis wisata apabila destinasi memiliki kemampuan lebih bila dapat membangun minat berkunjung (Zerva, 2015; Hidayatullah et al., 2020b). Tujuan utama dari perusahaan adalah membangun dan mempertahankan posisi yang tepat dari merek tertentu di benak konsumen, untuk membangun minat berkunjung, sehingga mengambil keputusan untuk berkunjung. Saat konsumen ingin membeli suatu produk, nama merek langsung muncul dalam pikiran, hal tersebut mencerminkan merek memiliki ekuitas yang tinggi. Ekuitas merek memainkan peran penting dalam meningkatkan miat berkunjung wisatawan (Setyanta, 2018; Muhammad \& Abdurachman, 2009).

Prospek dan potensi yang menjanjikan pada Jatim Park 3 dari sisi pertumbuhan sebagai salah satu tempat wisata yang ada di Kota Batu merupakan salah satu dasar penelitian ini perlu dila-ku-kan. Hal yang menarik adalah bagaimana penilaian dari konsumen terhadap social media marketing yang dilakukan oleh Jatim Park 3 melalui akun social media Facebook dan Instagram yang dikelola perusahaan yang diukur oleh dimensi social media marketing, ekuitas merek, dan citra destinasi yang telah ditentukan terhadap minat berkunjung wisatawan.

\section{TINJAUAN LITERATUR}

\section{Sosial Media Marketing}

Social media marketing merupakan suatu aktivias pemasaran yang digunakan dalam membangun kesadaran, pengakuan, pengingat, dan tindakan bagi merek melalui social media. Secara bertahap social media marketing diimplementasikan dalam pemasaran yang ada pada rencana perusahaan (Nadda et al., 2015). Sehingga dapat disimpulkan social media marketing merupakan aktivitas kegiatan pemasaran yang dilakukan dalam platform social media, dimana digunakan untuk membangun kesadaran, pengakuan, loyalitas terhadap merek.

\section{Ekuitas merek}

Suatu nilai yang memungkinkan suatu merek mendapatkan kekuatan, daya tahan, dan keunggulan yang dapat membedakan dengan merek pesaing dan juga apa yang telah dilihat, didengar, dipelajari, dipikirkan dan dirasakan oleh konsumen akan suatu merek (Simon \& Sullivan, 1993; Kotler \& Keller, 2009).

\section{Citra destinasi}

Citra destinasi merupakan gambaran kesan menyeluruh yang dibuat dalam pikiran wisatawan (Hosany et al., 2007). Sementara menurut (Kock et al., 2016), citra destinasi didefinisikan tidak hanya sebagai atribut tujuan tetapi juga keseluruhan kesan yang ditampilkan oleh tujuan. Selanjutnya menurut (Gallarza et al., 2002), konsep citra destinasi sebagai ekspresi dari semua pengetahuan objektif, prasangka, imajinasi dan pemikiran emosional individu atau kelompok tentang lokasi tertentu.

\section{Minat Berkunjung}

Minat berkunjung kembali adalah keadaan mental seseorang yang menggambarkan rencana untuk dapat melakukan beberapa tindakan dalam jangka waktu tertentu (Hidayatullah et al., 2020a). Keputusan merupakan seleksi atas dua atau lebih dari alternatif yang ada. Dalam hal ini, pilihan alternatif harus tersedia ketika proses penentuan keputusan dilakukan. Pilihan alternatif digunakan sebagai perbandingan atau acuan ketika keputusan akan ditentukan (Hargrove, 2011). 


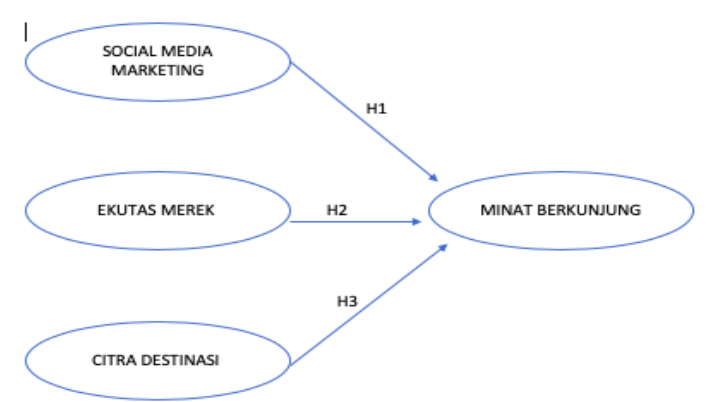

Gambar 1: Kerangka Konseptual Penelitian

\section{Hipotesis}

H1: Terdapat pengaruh Social Media Marketing terhadap Minat Berkunjung.

H2: Terdapat pengaruh Ekuitas Merek terhadap Minat Berkunjung.

H3: Terdapat pengaruh Citra Destinasi terhadap Minat Berkunjung.

\section{METODE}

Penelitian dilakukan dengan pengkajian deskriptif kuantitatif dengan melihat situasi yang muncul. Dengan social media marketing, ekuitas merek, dan citra destinasi sebagai variabel bebas, dan minat berkunjung sebagai variable terikat menjadi variable yang akan diteliti. Survey lokasi dengan penyebaran kuesioner menjadi bahan untuk pengumpulan data. Adapun lokasi penelitian yang diambil adalah Jatim Park 3, salah satu destinasi wisata milik Jatim Park Group yang ada di Kota Batu Jawa Timur. Populasi dalam penelitian ini adalah pengikut social media Jatim Park 3 di Facebook yang berjumlah 1.680 pengikut (terakhir diakses 1 Juni 2018), Hasil perhitungan 323 responden jumlah sampel yang menjadi responden terlalu banyak, karena keterbatasan waktu, tenaga dan biaya, peneliti hanya mengambil 150 responden dari pengikut Jatim Park 3 di Facebook. Regresi liner berganda dan uji hipotesis digunakan sebagai analisis data.

\section{HASIL DAN PEMBAHASAN}

\section{Analisis Regresi}

Untuk mengetahui pengaruh Social Media Marketing, Ekuitas Merek dan Citra Destinasi terhadap Minat Berkunjung digunakan model regresi dengan bentuk persamaan:

$$
Y=a+b_{1} X_{1}+b_{2} X_{2}+b_{3} X_{3}+\varepsilon
$$

Adapun hasil regresi dapat dilihat pada Tabel 1.

Tabel 1 : Persamaan Regresi

\begin{tabular}{|c|c|c|c|}
\hline Model & $\begin{array}{c}\begin{array}{c}\text { Standard- } \\
\text { ized Coeffi- } \\
\text { cients }\end{array} \\
\text { Beta }\end{array}$ & $T$ & Sig. \\
\hline $\begin{array}{l}\text { Sosial Me- } \\
\text { dia Mar- } \\
\text { keting (X1) }\end{array}$ & 0,565 & 9,193 & 0,000 \\
\hline $\begin{array}{l}\text { Ekuitas } \\
\text { Merek (X2) }\end{array}$ & 0,306 & 4,972 & 0,000 \\
\hline $\begin{array}{l}\text { Citra Des- } \\
\text { tinasi }(\mathrm{X} 3)\end{array}$ & $-0,066$ & $-1,237$ & 0,218 \\
\hline $\begin{array}{l}\text { Dependent } \\
\text { Variabel }\end{array}$ & \multicolumn{3}{|c|}{ Minat Berkunjung (Y) } \\
\hline Constant & 0.551 & & \\
\hline $\mathrm{R}$ & 0.769 & & \\
\hline $\mathrm{R}_{2}$ & 0,591 & & \\
\hline $\begin{array}{l}\mathrm{R}_{\text {2Adjusted }} \\
\mathrm{F} \text { hitung }\end{array}$ & $\begin{array}{l}0,583 \\
70,435\end{array}$ & & \\
\hline Probability & 0,000 & & \\
\hline Result & $\begin{array}{l}Y=0,551+ \\
0,066 X_{3}+e\end{array}$ & $5 X_{1}$ & $06 \mathrm{X}_{2}$ \\
\hline
\end{tabular}

Sumber: Data Primer diolah (2020)

Hasil regresi menunjukan jika social media marketing (X1) dan Ekuitas merek (X2) berpengaruh signifikan terhadap minat berkunjung $(\mathrm{Y})$, dibuktikan dengan nilai signifikan lebih kecil dari alpha $(0,05)$ atau $(5 \%)$. Besarnya nilai $R_{2}$ atau $R$ square yang terdapat pada tabel Model Summary adalah sebesar 0,591, hal ini menunjukan bahwa kontribusi atau sumbangan pengaruh $X_{1}$ dan $X_{2}$ terhadap $\mathrm{Y}$ adalah sebesar 59,1 \%, sementara sisanya sebesar $40,9 \%$ merupakan kontribusi dari variabel-variabel lain yang tidak dimasukan dalam penelitian ini. Sementara itu nilai e $=\sqrt{ }(1-0,591)=0,639$

Untuk mengetahui apakah model regresi diatas sudah benar atau salah, diperlukan uji hipotesis. Uji hipotesis menggunakan angka $\mathrm{F}$ sebagaimana hasil output hasil regresi model I diperoleh hasil $\mathrm{F}$ hitung 70,435 dengan nilai signifikan 0,000 . Hal ini berarti $0,000<0,05$ maka Ho ditolak dan H1 diterima, artinya ada hubungan antara social media marketing, ekuitas merek, dan citra destinasi terhadap minat berkunjung wisatawan. 


\section{Pengujian Hipotesis}

Selanjutnya hasil pengujian hipotesis dalam penelitian ini sebagai berikut:

\section{Uji Hipotesis ke 1}

\section{Pengaruh Social Media Marketing tehadap Minat Berkunjung}

Social media marketing berpengaruh terhadap visit intention, yang berarti bahwa peningkatan social media marketing dapat meningkatkan minat berkunjung. Social media marketing yang dibangun Jatim Park 3 dengan advantegeous campaign, relevant content, frequently update is content, popular content menunjukkan bahwa Jatim Park 3 telah melakukan aktivitas kegiatan pemasaran melalui social media dengan memberikan kampanye yang bermanfaat, membuat kontent yang relevan dengan lini bisnisnya, dan melakukan perbaharuan terhadap konten yang dibuat dan berminat untuk berkunjung. Konsumen yang telah berminat berkunjung ke Jatim Park 3 akan memberikan rekomendasi dan mereferensikan Jatim Park 3 untuk kemudian berminat mengunjungi Jatim Park 3. Hasil penelitian ini sejalan dengan (Balakrishnan et al., 2014; Laksamana, 2018) yang menyatakan bahwa social media marketing berpengaruh terhadap minat beli.

\section{Uji Hipotesis ke 2}

\section{Pengaruh Ekuitas Merek terhadap Minat Berkunjung}

Brand Equity/Ekuitas Merek berpengaruh terhadap visit intention, yang berarti bahwa peningkatan brand equity dapat meningkatkan minat berkunjung. Brand equity yang dibangun Jatim Park 3 dengan brand awareness, brand image, dan brand loyalty, dimana konsumen akan mempersepsikan Jatim Park 3 dikenal sebagai tempat wisata dan edukasi berpengaruh terhadap minat berkunjung yang diawal dengan awareness, konsumen akan mudah mengingat Jatim Park 3 sehingga bersedia mengikuti Jatim Park 3 pada social media untuk menerima informasi berkaitan dengan informasi atraksi baru dan promosi yang diinformasikan pada social media Jatim Park 3 dan berminat untuk berkunjung. Konsumen yang telah berminat berkunjung ke Jatim Park 3 akan memberikan rekomendasi dan mereferensikan Jatim Park 3 untuk kemudian berminat mengunjungi
Jatim Park 3. Sebagaimana pendapat (Banytè et al., 2007; Agusli \& Kunto, 2013), minat beli menunjukkan bahwa konsumen akan mengikuti pengalaman, preferensi, dan lingkungan eksternal untuk mengumpulkan informasi, mengevaluasi alternatif, dan membuat keputusan. Hasil penelitian ini sejalan dengan (Nam et al., 2011; Cobb-Walgren et al., 1995), yang menyatakan bahwa brand equity berpengaruh terhadap minat beli.

\section{Uji Hipotesis ke 3}

\section{Pengaruh Citra Destinasi terhadap Minat Berkunjung}

Citra destinasi tidak berpengaruh secara signifikan terhadap Minat berkunjung, karena nilai probabilitasnya $>0,05$ yaitu 0,218. Kesimpulan hipotesis ketiga secara statistik tidak teruji. Penelitian ini menggambarkan bahwa meskipun adanya faktor citra des-tinasi yang dimiliki oleh Jatim Park 3, tetapi tidak menimbulkan adanya minat berkunjung bagi wisatawan yang berkunjung ke Jatim Park 3, yang mana jika fungsi dimensi dari citra destinasi sebagai Citra destinasi kognitif, Citra destinasi yang unik, dan Citra destinasi afektif, maka tidak begitu berpengaruh bagi terciptanya minat berkunjung pada wisatawan. Hasil ini bertolak belakang dengan penelitian yang dilakukan oleh (Ahmad, 2018) dimana hasilnya mengindikasikan bahwa citra kognitif berpengaruh langsung terhadap intensi wisatawan untuk berkunjung kembali ke Sulawesi Selatan. Citra kognitif juga berpengaruh tidak langsung terhadap intensi wisatawan untuk berkunjung kembali melalui citra afektif.

\section{Pembahasan}

Social media marketing dalam hal ini relevant content tercermin dari informasi yang diberikan social media Jatim Park 3 sesuai dengan lini bisnis yang bergerak di bidang pariwasata dan diketahui banyak orang mampu mempengaruhi minat konsumen untuk mempertimbangkan untuk berkunjung, untuk selanjutnya bersedia berkunjung ke Jatim Park 3. Ekuitas merek yang terbentuk dari brand awareness, brand image, dan brand loyalty pada Jatim Park 3, dalam hal ini brand image, karena Jatim Park 3 dikenal sebagai tempat wisata edukasi yang menawarkan atraksi-atraksi berkualitas berpengaruh terhadap minat berkunjung yang ter- 
bentuk dari interest, desire, conviction, yaitu setelah mengetahui citra dari Jatim Park 3 konsumen bersedia berkunjung dan selanjutnya mereferensikan Jatim Park 3 pada teman saat ingin berkunjung ke Jatim Park 3. Selain hal tersebut, keberadaan Jatim Park 3 memang sudah sangat akrab di kalangan masyarakat di Malang Raya dimana wahana yang ada tidak terlepas dari wahana yang update sesuai dengan selera masyarakat yang kekinian. Hal ini tidak terlepas dari inovasi dan jiwa intrepreneurial marketing pengelola, dimana dengan memiliki jiwa entrepreneurial marketing kita akan senantiasa melakukan inovasi dan kreasi yang terus menerus untuk memenangkan persaingan dan meningkatkan kinerja pemasaran (Hidayatullah et al., 2019; Khouroh et al., 2020).

Peran sistem informasi pemasaran sangatlah penting di dalam marketing suatu destinasi, dimana jaman sekarang semua informasi bersifat online sehingga informasi yang ada harus benar-benar menarik wisatawan untuk mau datang atau berkunjung terutama wisatawan usia millennial yang selalu ingin cepat, lengkap dan menarik (Hidayatullah et al., 2020a). Sehingga dalam menampilkan informasi di media social hendaknya memperhatikan isi dan tampilan dari yang akan ditampilkan (Rakhmadian et al., 2017). Hal yang tidak kalah pentingnya dalam pengembangan suatu obyek wisata, selain citra destinasi, ekuitas dan sistem informasi pemasaran adalah bagaimana suatu obyek wisata dapat berkembang secara terus menerus dengan menampilkan suasana yang berbeda dalam setiap lokasi. Seperti halnya Jatim Park 1, 2 dan 3 semua wahana yang ada selalu berbeda dalam setiap lokasinya. Hal ini tidak terlepas dari bagaimana pengelola Jatim Park Group dapat berinvestasi dengan smart (Windhyastiti et al., 2019). Untuk mendukung usaha pariwisata lokal yang ada Jatim Park group juga dapat bekerja sama dengan destinasi lokal dengan membuat sistem wisata berkelanjutan atau pemberdayaan Kelompok sadar wisata (pokdarwis) yang ada di Kota Batu (Hidayatullah et al., 2018; Hidayatullah et al., 2017).

\section{SIMPULAN}

Kesimpulan dalam penelitian ini adalah Social media marketing berpengaruh terhadap visit intention. Brand Equity/Ekuitas
Merek berpengaruh terhadap visit intention. Citra destinasi tidak berpengaruh signifikan terhadap Minat berkunjung. Peran social media dalam memperkenalkan suatu produk barang atau jasa saat ini sangat berperan penting dimana era saat ini merupakan era online dan generasi millennial yang menguasai sehingga mau tidak mau perusahaan harus mengikuti keinginan dan trend tersebut dengan memasarkan produk/jasa melalui media social. Ekuitas merk merupakan brand yang apabila sudah melekat baik oleh konsumen maka akan terus baik selamanya. Demikian halnya dengan Jatim Park yang sudah mengembangkan usahanya dibidang pariwisata dengan membuka Jatim Park 1 sampai Jatim Park 3 yang kesemuanya sukses dan terus berkembang. Hal ini karena pihak pengelola yang senantiasa menjaga secara konsisten merek yang sudah melekat.

Penelitian ini membahas tentang hubungan antara social media, ekuitas merk, dan citra destinasi. Rekomendasi yang dapat diberikan pada peneliti lain adalah dapat meneliti hubungan yang lebih luas lagi selain yang penulis lakukan saat ini, seperti; atraksi, emenitas maupun aksesibiltas yang ada di Jatim Park 3, serta rekomendasi yang disarankan bagi perusahaan adalah hendaknya mempertahankan promosi yang ada melalui social media serta ekuitas merk yang sudah ada. Di sisi lain tentang citra destinasi perusahaan perlu ditingkatkan lagi mengingat hasil yang tidak signifikan. Walaupun Jatim Park 3 sudah memiliki nama besar, namun minat berkunjung ternyata berasal dari social media dan ekuitas merk. Konsep citra destinasi dapat digambarkan sebagai ekspresi dari pengetahuan objektif yang diperoleh, prasangka, imajinasi dan pemikiran emosional individu atau kelompok tentang lokasi tertentu.

\section{DAFTAR PUSTAKA}

Agusli, D., \& Kunto, S. (2013). Ekuitas Merek Terhadap Minat Beli Konsumen Midtown Hotel Surabaya. Jurnal Manajemen Pemasaran Petra.

Ahmad, A. (2018). CITRA DESTINASI DAN PENGARUHNYA TERHADAP INTENSI UNTUK BERKUNJUNG KEMBALI DI SULAWESI SELATAN SEBAGAI DESTINASI PARIWISATA. Sosiohumaniora. 
https://doi.org/10.24198/sosiohumani ora.v20i3.14050

Alvianna, S., Patalo, R. G., Hidayatullah, S., \& Rachmawati, I. K. (2020). Pengaruh Attraction, Accessibillity, Amenity, Ancillary Terhadap Kepuasan Generasi Millenial Berkunjung ke Tempat Wisata. 4, 53-59.

https://doi.org/10.34013/jk.v4i2.41

Balakrishnan, B. K. P. D., Dahnil, M. I., \& Yi, W. J. (2014). The Impact of Social Media Marketing Medium toward Purchase Intention and Brand Loyalty among Generation Y. Procedia - Social and Behavioral Sciences. https://doi.org/10.1016/j.sbspro.2014.0 7.032

Banytè, J., Jokšaitè, E., \& Virvilaitè, R. (2007). Relationship of Consumer Attitude and Brand: Emotional Aspect. Engineering. https://doi.org/10.5755/J01.EE.52.2.114 76

Cobb-Walgren, C. J., Ruble, C. A., \& Donthu, N. (1995). Brand equity, brand preference, and purchase intent. Journal of Advertising. https://doi.org/10.1080/00913367.1995. 10673481

Gallarza, M. G., Saura, I. G., \& García, H. C. (2002). Destination image. Annals of Tourism https://doi.org/10.1016/s01607383(01)00031-7

Hargrove, C. M. (2011). Heritage tourism. In Tourism and Hospitality: Issues and Developments.

https://doi.org/10.18848/1832-

2077/cgp/v04i04/54509

Hidayatullah, S., Firdiansjah, A., Patalo, R. G., \& Waris, A. (2019). The effect of entrepreneurial marketing and competitive advantage on marketing performance. International Journal of Scientific and Technology Research.

Hidayatullah, S., Malang, U. M., Khouroh, U., Malang, U. M., Windhyastiti, I., \& Malang, U. M. (2018). Development of Tourist Village Model Through "Pokdarwis" Empowerment and Information Technology Utilization. European Journal of Business and Management, January. https://doi.org/10.7176/ejbm-10-23-12

Hidayatullah, S., Rachmawati, I. K.,
Aristanto, E., Waris, A., \& Patalo, R. G. (2020a). Peran Sistem Informasi Pemasaran, Kualitas Pelayanan dan Entrepreneurial marketing serta Kepuasan Terhadap Loyalitas Generasi Milenial Berkunjung ke Tempat Wisata. Jurnal Ilmiah Bisnis Dan Ekonomi Asia. https://doi.org/10.32812/jibeka.v14i1.1 84

Hidayatullah, S., Rachmawati, I. K., Aristanto, E., Waris, A., \& Patalo, R. G. (2020b). Peran Sistem Informasi Pemasaran , Kualitas Pelayanan dan Entrepreneurial marketing serta Kepuasan Terhadap Loyalitas Generasi Milenial Berkunjung ke Tempat Wisata. https://doi.org/10.32812/jibeka.v14i1.1 48

Hidayatullah, S., Rachmawati, I. K., \& Khouroh, U. (2017). The Effectivity of " Pokdarwis "Role on Successfully Marketing of Tourism Village Towards " Mega Tourism: Batu City For The World ." August, 978-979.

Hidayatullah, S., Windhyastiti, I., Patalo, R. G., \& Rachmawati, I. K. (2016). Citra Destinasi : Pengaruhnya terhadap Kepuasan dan Loyalitas Wisatawan yang Berkunjung ke Gunung Bromo. 96-108.

Hosany, S., Ekinci, Y., \& Uysal, M. (2007). Destination image and destination personality. International Journal of Culture, Tourism and Hospitality Research. https://doi.org/10.1108/1750618071072 9619

Jayani, D. H. (2019). Berapa Pengguna Internet di Indonesia? Databoks.

Khouroh, U., Sudiro, A., Rahayu, M., \& Indrawati, N. K. (2020). The mediating effect of entrepreneurial marketing in the relationship between environmental turbulence and dynamic capability with sustainable competitive advantage: An empirical study in Indonesian MSMEs. Management Science Letters. https://doi.org/10.5267/j.msl.2019.9.00 7

Kock, F., Josiassen, A., \& Assaf, A. G. (2016). Advancing destination image: The destination content model. Annals of Tourism Research. https://doi.org/10.1016/j.annals.2016.0 7.003

Kotler, P., \& Keller, K. L. (2009). Marketing 
management (13th ed.). In Prentice Hall.

Laksamana, P. (2018). Impact of Social Media Marketing on Purchase Intention and Brand Loyalty: Evidence from Indonesia's Banking Industry. International Review of Management and Marketing.

Muhammad, \& Abdurachman, E. (2009). Analisis elemen-elemen ekuitas merek. 348 Journal of Business Strategy and Execution Vol.

Nadda, V. K., Dadwal, S. S., \& Firdous, A. (2015). Social media marketing. In Handbook of Research on Integrating Social Media into Strategic Marketing. https://doi.org/10.4018/978-1-46668353-2.ch021

Nam, J., Ekinci, Y., \& Whyatt, G. (2011). Brand equity, brand loyalty and consumer satisfaction. Annals of Tourism Research.

https://doi.org/10.1016/j.annals.2011.0 1.015

Rakhmadian, M., Hidayatullah, S., Respati, H., \& Malang, U. M. (2017). Analisis Kualitas Sistem Dan Kualitas Informasi Terhadap Kepuasan Pemakai Sistem Informasi Akademik Dosen. Seminar Nasional Sistem Informasi, September, 665675.

Setyanta, B. (2018). PERAN EKUITAS MERK TERHADAP LOYALITAS MERK BARBERSHOP DI KOTA YOGYAKARTA. Capital: Jurnal Ekonomi Dan Manajemen. https://doi.org/10.25273/capital.v1i2.2 320

Simon, C. J., \& Sullivan, M. W. (1993). The Measurement and Determinants of Brand Equity: A Financial Approach. Marketing Science. https://doi.org/10.1287/mksc.12.1.28

Windhyastiti, I., Hidayatullah, S., \& Khouroh, U. (2019). How to increase city investment attraction. International Journal of Scientific and Technology Research.

Zerva, K. (2015). Visiting authenticity on Los Angeles gang tours: Tourists backstage. Tourism Management. https://doi.org/10.1016/j.tourman.2014 .08 .004 